\title{
MODELAGEM E SIMULAÇÃO PARA MELHORIA DE DESEMPENHO DO CIRCUITO DE MOAGEM DA VANÁDIO DE MARACÁS
}

\author{
W. L. GOMES ${ }^{1}$, I. A. COSTA ${ }^{2}$, C. V. P. MARQUES ${ }^{2}$, T. L. A. JATOBÁ ${ }^{1}$, H. DELBONI JR. ${ }^{1}$, V. P. GIACON ${ }^{1}$ \\ Escola Politécnica da Universidade de São Paulo, Largo Resources Ltd. ${ }^{2}$ \\ wellingtonlacerdagomes@gmail.com ${ }^{1}$
}

Submetido 21/11/2017 - Aceito 25/11/2017

DOI: $10.15628 /$ holos.2017.6588

\section{RESUMO}

O controle da granulometria do produto final do circuito de moagem da Vanádio de maracás é fundamental para uma boa operação da usina, em vista de que a geração de um produto grosso e, consequentemente, a não liberação das partículas de magnética e sílica acarretam em perdas metalúrgicas de vanádio na etapa de concentração magnética e altas concentrações de sílica geram grandes problemas operacionais na etapa de calcinação. Por outro lado a geração de um produto muito fino promove dificuldades na etapa de filtragem. 0 presente estudo teve como objetivo estabelecer medidas de processo para as etapas de moagem, classificação e concentração magnética que promovessem melhoria de desempenho do circuito industrial, de forma a aumentar a produção e a recuperação metalúrgica de vanádio. Para tanto foi estabelecido um diagnóstico atualizado e detalhado do desempenho do circuito industrial, com base em uma campanha de amostragem global do circuito industrial. Com base nos dados obtidos na campanha de amostragem foram realizadas calibrações de modelos matemáticos para cada um dos equipamentos amostrados, bem como a integração dos mesmos representando assim a operação típica da do circuito, tal plataforma foi denominada de Caso Base. A partir do Caso Base uma série de cenários foram simulados, com alternativas de processo para melhorar o desempenho de processo da etapa de classificação. Como resultado, tal circunstância promoveu aumento da produção da etapa de moagem, além de aumento da recuperação metalúrgica de vanádio e da qualidade do concentrado final.

PALAVRAS-CHAVE: classificação, by-pass, concentração magnética.

\section{MODELLING AND SIMULATION FOR INCREASING PERFORMANCE OF GRINDING CIRCUIT OF THE VANÁDIO DE MARACÁS}

\begin{abstract}
Control of particle-size distribution of grinded final product of is essential for a good plant operation, once the generation of coarse material and, consequently, the non-liberation of magnetite and silicate particles, results in metallurgical losses of vanadium in magnetic concentration stage and operational problems in the calcination step. On the other hand, the generation of a very fine product causes difficulties in the filtration stage. This article aims to evaluate the process parameters for grinding, classification and magnetic concentration steps that would bring about increased performance, improving the production and metallurgical recovery of vanadium. For this purpose, an
\end{abstract}

updated and detailed survey of the plant performance was done, based on a global sampling of the mentioned steps. From the data obtained in the sampling campaign, calibrations of mathematical models were performed for each one of the sampled equipment representing the typical operation of the circuit, such platform was called Base Case. From the Base Case, a series of scenarios were carried out, which consisted in alternatives to improve performance of the classification stage. Therefore increased production in grinding, increased metallurgical recovery of vanadium and improved quality of the final concentrate in magnetic concentration stage.

KEYWORDS: classification, by-pass, magnetic concentration. 


\section{INTRODUÇÃO}

O processo de beneficiamento do minério de vanádio de Maracás, BA, inclui britagem com escalpe magnético, moagem de bolas direta e fechada com hidrociclones, concentração magnética, filtragem primária, calcinação, lixiviação, filtragem secundária e subsequentes etapas de processos químicos para produção de pentóxido de vanádio.

Um estudo foi realizado sobre a operação do circuito de moagem e concentração magnética da Vanádio de Maracás (VMSA). O trabalho teve como objetivo elaborar um diagnóstico da operação atual em relação ao desempenho e eficiência de processo, bem como recomendar ações a serem tomadas nos pontos indicados pelo diagnóstico com possibilidade de melhoria de processo. As ações recomendadas foram estudadas por meio de modelagem matemática e simulações de processo.

\section{REVISÃO DA LITERATURA E METODOLOGIA}

O trabalho foi baseado em uma campanha de amostragem do respectivo circuito industrial. A partir dos dados e das informações obtidas na campanha de amostragem foram realizadas calibrações de modelos matemáticos de cada equipamento amostrado e a integração dos mesmos de modo a configurar uma plataforma representativa da operação atual do circuito denominada Caso Base. A calibração dos modelos matemáticos de processo para os equipamentos individuais, bem como a integração dos mesmos foram realizadas com o auxílio do software JKSimMet 6.1. Os modelos matemáticos utilizados para calibrar os equipamentos do circuito de moagem VMSA foram o Perfect Mixing Model, PMM (WHITEN, 1976) para o moinho de bolas e o modelo de Nageswararao (1978 e 1995) para hidrociclones.

O Perfect Mixing Model é um modelo de balanço populacional, no qual assume-se que todo o material no interior do moinho está perfeitamente misturado. Deste modo, o moinho se comporta como um equipamento de transformação de granulometria onde o material alimentado na i-ésima fração mais o material moído das frações mais grossas até o tamanho da i-ésima fração é igual ao produto da i-ésima fração somado ao material fragmentado da i-ésima fração.

O modelo de Nageswararao, o qual foi desenvolvido diretamente a partir do modelo de Lynch e Rao (1975), baseia-se na curva de partição padrão de classificação e foi elaborado com base em dados experimentais obtidos a partir de testes em escala piloto. Nageswararao estimou expoentes empíricos para quatro equações referentes ao cálculo dos parâmetros, que descrevem o processo de classificação em hidrociclones, quais sejam, diâmetro mediano de partição, partição de água e de polpa ao underflow e vazão volumétrica da alimentação.

\section{RESULTADOS E DISCUSSÃO}

O objetivo de se adotar um Caso Base consistiu em se determinar diagnósticos da operação atual do circuito de moagem e concentração magnética da VMSA, estabelecendo assim as respectivas referências que balizaram os cenários simulados. O Caso Base do circuito de moagem consistiu de moinho de bolas $(4,1 \times 8,0 \mathrm{~m})$, operando com $35 \%$ de grau de enchimento e $75 \%$ da 
velocidade crítica. A potência aplicada ao moinho foi de $2.119 \mathrm{~kW}$. A etapa de classificação operou com 2 hidrociclones de 20", com vortex e apex de $170 \mathrm{~mm}$ e $110 \mathrm{~mm}$, respectivamente, e pressão de operação de $66 \mathrm{kPa}$. A etapa de concentração magnética contém duas linhas semelhantes em paralelo, com um estágio rougher e um cleaner cada. Todos os estágios de concentração magnética consistem de separadores de tambor a úmido de 1,5 kG. A Figura 1, a seguir, ilustra o fluxograma de processo do circuito de moagem e concentração magnética da VMSA e o sumário do balanço de massas para o Caso Base.

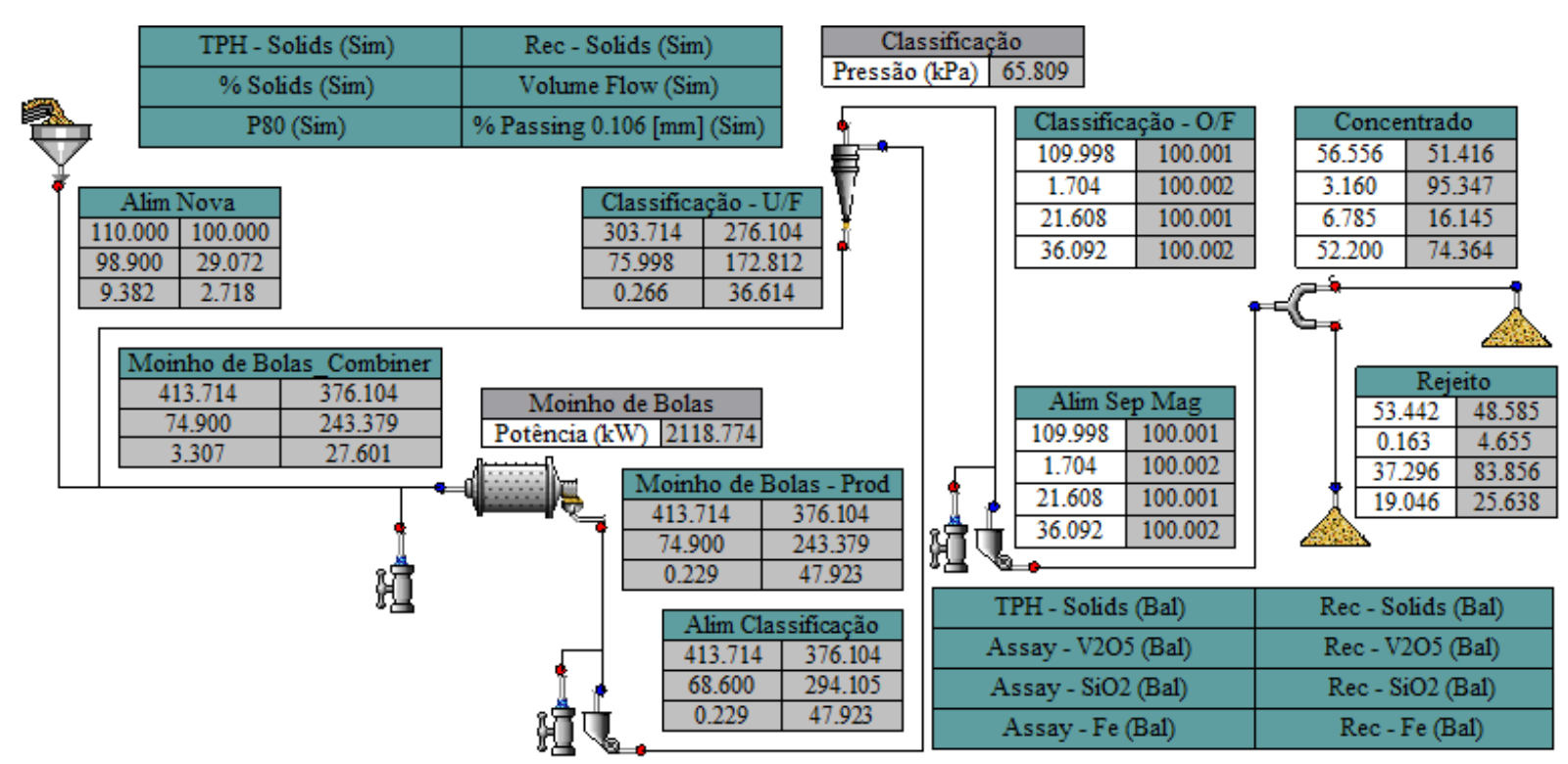

Figura 1. Fluxograma de processo do Caso Base do circuito industrial da VMSA.

\subsection{Caso Base - Circuito de Moagem}

Os resultados do Caso Base para o circuito de moagem indicaram:

- $\quad$ O Caso Base do circuito de moagem apresentou produção de $110 \mathrm{t} / \mathrm{h}$ com F 80 de 9,38 mm e produto final (overflow classificação) com $\mathrm{P}_{80}$ de $0,108 \mathrm{~mm}$ e $20,8 \%$ retido na malha 0,106 mm (150\# Tyler), indicando relação de redução global de 87 e carga circulante de $276 \%$, esta última considerada adequada ao circuito;

- $\quad$ Ainda o Caso Base do circuito de moagem da VMSA indicou potência específica de 19,3 $\mathrm{kWh} / \mathrm{t}$ e WI operacional de 22,4 kWh/t, resultando segundo Rowland eficiência operacional de moagem de 63\%, indicando desempenho muito baixo. Em termos de geração de produto abaixo de 0,106 $\mathrm{mm}$ (150\# Tyler) o circuito de moagem da VMSA indicou para o

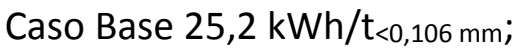

- $\quad$ O moinho de bolas indicou alta cinética de fragmentação para partículas maiores que 0,600 $\mathrm{mm}$, em contrapartida apresentou significativa redução da cinética de fragmentação para partículas menores, principalmente para a fração $-0,600+0,150 \mathrm{~mm}$, considerada como a fração granulométrica crítica do circuito industrial;

- $\quad$ Foi indicado para o Caso Base eficiência de classificação de finos de $44 \%$ para a malha de controle $0,106 \mathrm{~mm}$ (150\# Tyler) índice considerado muito baixo, isto é, $56 \%$ do material abaixo de 0,106 $\mathrm{mm}$ que alimenta a bateria de hidrociclones da classificação é reencaminhada ao moinho de bolas, fato que acarreta em aumento da carga circulante. 
Uma vez que altas cargas circulantes denotam impossibilidade de aumento de vazão de alimentação nova de sólidos, mantendo-se $0 \mathrm{P}_{80}$ do produto da moagem em circuito fechado, tal conjuntura pode gerar um gargalo para o circuito de moagem;

- A partição de água para o underflow da etapa de classificação, responsável pelo arraste de finos, foi de $51 \%$ considerada extremamente alta, indicando baixo desempenho da etapa de classificação e grande arraste de finos para o underflow. Além do mais a partição para o underflow do material abaixo de $0,038 \mathrm{~mm}$ foi de $58 \%$, mais uma vez confirmando o alto by-pass de finos.

Os resultados do Caso Base para o circuito de concentração magnética indicaram:

- O circuito de concentração magnética indicou para o Caso Base recuperação mássica e metalúrgica de $\mathrm{V}_{2} \mathrm{O}_{5}$ para o concentrado de $51 \%$ e $95 \%$, respectivamente. Ainda, os teores de $\mathrm{V}_{2} \mathrm{O}_{5}$ e $\mathrm{SiO}_{2}$ no concentrado foram de $3,2 \%$ e $6,8 \%$, respectivamente. Este último considerado extremamente alto, o que acarreta em graves problemas para a etapa subsequente de calcinação;

- $\quad$ O teor de $\mathrm{SiO}_{2}$ do concentrado na fração $+0,150 \mathrm{~mm}$ foi bastante elevado $(23,2 \%)$, correspondendo a $27,4 \%$ da sílica contida no concentrado. A maior fonte de $\mathrm{SiO}_{2}(39,6 \%)$ foi, porém, a fração $-0,038 \mathrm{~mm}(1,52 \mathrm{t} / \mathrm{h})$;

- $\quad$ Presença de grãos leves e grossos mistos $(+0,106 \mathrm{~mm})$, com pouca magnetita porém o suficiente para serem atraídos pelo rolo magnético, limitando a seletividade da concentração.

\subsubsection{Discussão da Etapa de Concentração Magnética}

A partir do Caso Base da etapa de concentração magnética foram constatadas as seguintes conclusões da respectiva etapa:

- $\quad$ O aprisionamento de partículas não susceptíveis magneticamente, de tamanhos diversos (maior impedimento para partículas maiores), devido à dificuldade de deslocamento livre na polpa no entorno do rolo magnético, leva estas partículas não magnéticas liberadas ao fluxo magnético. As intensas forças magnéticas criam uma rede física difícil de ser rompida (floculação magnética), tornando a viscosidade da polpa quanto maior pior para a seletividade processo. Há assim influência da porcentagem de sólidos, da geometria e do set-up do equipamento;

- Há arraste de finos de toda espécie, inclusive as indesejadas ricas em $\mathrm{SiO}_{2}$, pela água encaminhada ao fluxo magnético. Neste caso, quanto menor a porcentagem de sólidos maior a velocidade da polpa e menores o tempo de residência e a recuperação de magnéticos;

- $\quad$ A vazão de SiO2 no concentrado pode ser entendida como a seguinte equação:

$$
\text { SiO } 2_{\text {Conc. }}=S i O 2_{\text {Liberação }}+S i O 2_{\text {Aprisionamento }}+\text { SiO2 } 2_{\text {Arraste }}
$$

- $\quad$ Assim, se a capacidade volumétrica do circuito de concentração não tem folgas, reduzir a porcentagem de sólidos conduz a um aumento da seletividade, porém podendo implicar em perdas de recuperação de vanádio. Havendo margem instalada, a diluição acarreta em menores retenções por aprisionamento;

- $\quad$ A ocorrência substancial de $\mathrm{Fe}$ e $\mathrm{V}_{2} \mathrm{O}_{5}$ nos finos da alimentação $(-0,038 \mathrm{~mm})$, onde as forças magnéticas são menores, pois competem com as forças viscosas e com os impedimentos 
físicos ao deslocamento livre das partículas, pode contribuir para o arraste de finos magnéticos aos rejeitos, onde as vazões de água são maiores;

- $\quad$ Para as frações grossas, considera-se que na equação de incidência de $\mathrm{SiO}_{2}\left(\mathrm{SiO} 2_{\text {Conc. }}=\right.$ $\left.\mathrm{SiO} 2_{\text {Liberação }}+\mathrm{SiO} 2_{\text {Aprisionamento }}+\mathrm{SiO} 2_{\text {Arraste }}\right)$ o termo referente à contribuição do arraste hidráulico de $\mathrm{SiO}_{2}$ seja igual ou próximo a zero, restando as parcelas advindas da falta de liberação e do aprisionamento de partículas;

- As ineficiências obtidas na fração -0,038 mm são de difícil correção uma vez boa parte da cinética das partículas é influenciada pelas forças de arraste, estando as possibilidades de otimização vinculadas à capacidade de equipamentos suportarem condições operacionais mais favoráveis (baixa viscosidade da polpa, desmagnetização da polpa entre estágios rougher e cleaner, manutenção dos sprays de limpeza, etc.);

- Idealmente, otimizar a seletividade da operação industrial para não haver aprisionamento dos grãos de ganga, traria um potencial de redução de $14 \%$ da sílica total a partir da remoção desta parcela ( $\mathrm{SiO}_{2}$ aprisionamento), com uma queda de teor de $\mathrm{SiO}_{2}$ de 6,9\% para $6,0 \%$ no concentrado final, e uma perda insignificante de $\mathrm{V}_{2} \mathrm{O}_{5}$.

\subsection{Cenários Simulados - Circuito de Moagem}

De acordo com o diagnóstico do Caso Base o principal ponto de estudo mediante simulação de cenários para o circuito de moagem VMSA foi o aumento da eficiência de classificação. Assim foram simuladas alternativas que promovessem a redução do by-pass de finos e de água e, por conseguinte, da carga circulante do circuito por meio da adequação da porcentagem de sólidos de alimentação e adequação dos diâmetros de apex e vortex. Tais estudos compreenderam a simulação de 10 cenários distintos. A Tabela 1 na página seguinte apresenta a descrição dos cenários, assim como os principais resultados obtidos para cada um destes.

\subsubsection{Discussão dos Cenários Simulados}

Os cenários simulados (Cenários 1 a 10) indicaram que diluir a alimentação classificação, em conjunto com a adequação dos diâmetros de apex e vortex acarreta em benefícios para o desempenho do circuito aumentando a eficiência de classificação de finos desta etapa, por conseguinte, reduzindo o by-pass de finos e de água para o underflow e a carga circulante do circuito.

Um fato importante notado foi que os cenários simulados com diâmetro de vortex maior em relação ao Caso Base, porém com maior diluição da alimentação da classificação indicaram desempenho superior, com maior eficiência de classificação de finos, portanto menor carga circulante e by-pass de finos e de água para o underflow. Assim, constata-se que altas porcentagens de sólidos na alimentação de hidrociclonagens dificultam a classificação das partículas, pois estas competem pelo mesmo espaço gerando grande turbulência e interferência entre as mesmas. Fato que promove grande arraste das partículas finas para o underflow, as quais ficam presas na periferia dos hidrociclones pelas partículas mais grossas.

\subsection{Aplicação dos Cenários Simulados no Circuito Industrial}

Com base nos resultados dos cenários simulados para o circuito de moagem da VMSA foram aplicadas ao circuito industrial as alternativas para a etapa de classificação com diluição da 
Tabela 1. Descrição e resultados dos cenários simulados para o circuito de moagem VMSA.

\begin{tabular}{|c|c|c|c|c|c|c|c|c|c|c|c|c|c|c|}
\hline \multirow{2}{*}{ Cenários } & \multirow{2}{*}{ Descrição } & \multirow{2}{*}{$\begin{array}{l}\text { Vazão } \\
\text { Alim. } \\
\text { (t/h) }\end{array}$} & \multirow{2}{*}{$\begin{array}{c}F_{80} \\
(\mathrm{~mm})\end{array}$} & \multirow{2}{*}{$\begin{array}{c}\mathrm{P}_{80} \\
(\mathrm{~mm})\end{array}$} & \multirow{2}{*}{$\begin{array}{c}\text { Carga } \\
\text { Circulante } \\
(\%)\end{array}$} & \multirow{2}{*}{$\begin{array}{l}\mathrm{WI}_{\text {operacional }} \\
(\mathrm{kWh} / \mathrm{t})\end{array}$} & \multirow{2}{*}{$\begin{array}{c}\text { kWh/t de } \\
\text { geração } \\
<0,106 \mathrm{~mm}\end{array}$} & \multicolumn{3}{|c|}{$\begin{array}{c}\text { \% Sólidos } \\
\text { Classificação }\end{array}$} & \multicolumn{3}{|c|}{ Partição para o U/F (\%) } & \multirow{2}{*}{$\begin{array}{c}\text { Eficiência } \\
\text { de Class. } \\
0,106 \mathrm{~mm} \\
(\%)\end{array}$} \\
\hline & & & & & & & & Alim. & $U / F$ & $\mathrm{O} / \mathrm{F}$ & $\begin{array}{l}\text { Polpa } \\
\text { (vol) }\end{array}$ & Sólidos & Água & \\
\hline Caso Base & $\begin{array}{l}\text { Alimentação da classificação com } 68,6 \% \\
\text { de sólidos, diâmetros de apex de } 110 \\
\mathrm{~mm} \text { e vortex de } 170 \mathrm{~mm}\end{array}$ & 110 & 9,38 & 0,108 & 276 & 22,4 & 25,2 & 68,6 & 76,0 & 54,1 & 58,8 & 73,4 & 50,7 & 43,9 \\
\hline Cenário 1 & $\begin{array}{l}\text { Alimentação da classificação com } 63,8 \% \\
\text { de sólidos, diâmetros de apex de } 110 \\
\mathrm{~mm} \text { e vortex de } 170 \mathrm{~mm}\end{array}$ & 110 & 9,38 & 0,098 & 395 & 21,3 & 24,0 & 63,8 & 74,9 & 40,2 & 57,1 & 79,8 & 47,0 & 40,1 \\
\hline Cenário 2 & $\begin{array}{l}\text { Alimentação da classificação com } 61,6 \% \\
\text { de sólidos, diâmetros de apex de } 110 \\
\mathrm{~mm} \text { e vortex de } 170 \mathrm{~mm}\end{array}$ & 110 & 9,38 & 0,092 & 478 & 20,5 & 23,3 & 61,6 & 78,5 & 30,3 & 49,7 & 82,7 & 36,2 & 40,2 \\
\hline Cenário 3 & $\begin{array}{l}\text { Alimentação da classificação com } 62,7 \% \\
\text { de sólidos, modificação dos diâmetros de } \\
\text { apex para } 120 \mathrm{~mm} \text { e vortex para } 230 \mathrm{~mm}\end{array}$ & 110 & 9,38 & 0,099 & 306 & 21,4 & 24,2 & 62,7 & 76,8 & 40,1 & 49,4 & 75,4 & 38,3 & 47,8 \\
\hline Cenário 4 & $\begin{array}{l}\text { Alimentação da classificação com } 60,5 \% \\
\text { de sólidos, modificação dos diâmetros de } \\
\text { apex para } 120 \mathrm{~mm} \text { e vortex para } 230 \mathrm{~mm}\end{array}$ & 110 & 9,38 & 0,092 & 390 & 20,6 & 23,3 & 60,5 & 81,3 & 30,3 & 42,4 & 79,6 & 28,0 & 46,5 \\
\hline Cenário 5 & $\begin{array}{l}\text { Alimentação da classificação com } 62,4 \% \\
\text { de sólidos, modificação dos diâmetros de } \\
\text { apex para } 100 \mathrm{~mm} \text { e vortex para } 200 \mathrm{~mm}\end{array}$ & 110 & 9,38 & 0,100 & 250 & 21,4 & 24,2 & 62,4 & 80,0 & 40,3 & 42,1 & 71,4 & 29,7 & 54,9 \\
\hline Cenário 6 & $\begin{array}{l}\text { Alimentação da classificação com } 60,6 \% \\
\text { de sólidos, modificação dos diâmetros de } \\
\text { apex para } 100 \mathrm{~mm} \text { e vortex para } 200 \mathrm{~mm}\end{array}$ & 110 & 9,38 & 0,094 & 317 & 20,7 & 23,5 & 60,6 & 84,2 & 32,1 & 37,1 & 76,0 & 21,9 & 52,7 \\
\hline Cenário 7 & $\begin{array}{l}\text { Alimentação da classificação com } 62,2 \% \\
\text { de sólidos, modificação dos diâmetros de } \\
\text { apex para } 90 \mathrm{~mm} \text { e vortex para } 185 \mathrm{~mm}\end{array}$ & 110 & 9,38 & 0,100 & 227 & 21,4 & 24,2 & 62,2 & 82,1 & 40,1 & 38,0 & 69,4 & 24,9 & 58,7 \\
\hline Cenário 8 & $\begin{array}{l}\text { Alimentação da classificação com } 61,3 \% \\
\text { de sólidos, modificação dos diâmetros de } \\
\text { apex para } 90 \mathrm{~mm} \text { e vortex para } 185 \mathrm{~mm}\end{array}$ & 110 & 9,38 & 0,097 & 256 & 21,1 & 23,9 & 61,3 & 84,2 & 36,2 & 35,8 & 71,9 & 21,4 & 57,6 \\
\hline Cenário 9 & $\begin{array}{l}\text { Alimentação da classificação com } 62,1 \% \\
\text { de sólidos, modificação dos diâmetros de } \\
\text { apex para } 80 \mathrm{~mm} \text { e vortex para } 170 \mathrm{~mm}\end{array}$ & 110 & 9,38 & 0,100 & 204 & 21,5 & 24,3 & 62,1 & 84,4 & 40,3 & 34,0 & 67,1 & 20,3 & 62,8 \\
\hline Cenário 10 & $\begin{array}{l}\text { Alimentação da classificação com } 58,3 \% \\
\text { de sólidos, modificação dos diâmetros de } \\
\text { apex para } 80 \mathrm{~mm} \text { e vortex para } 170 \mathrm{~mm}\end{array}$ & 110 & 9,38 & 0,094 & 293 & 20,8 & 23,6 & 58,3 & 83,8 & 30,8 & 34,4 & 74,6 & 20,2 & 55,0 \\
\hline
\end{tabular}


alimentação e adequação dos diâmetros de apex e vortex, as quais indicaram resultados promissores em relação à redução do by-pass de finos, de água e da carga circulante.

Após o emprego das alternativas simuladas e estabilização da operação do circuito, uma nova campanha de amostragem foi conduzida no circuito industrial para avaliar o desempenho do mesmo depois da aplicação das modificações recomendadas. A partir dos dados da nova campanha foi realizada nova calibração do circuito de moagem, sendo esta denominada de Caso Base II.

Para o Caso Base II o circuito de moagem VMSA operou com $40 \%$ de grau de enchimento e $75 \%$ da velocidade crítica. A potência aplicada ao moinho foi de $2.275 \mathrm{~kW}$. A etapa de classificação operou com 2 hidrociclones de 20", com vortex e apex de $200 \mathrm{~mm}$ e $100 \mathrm{~mm}$, respectivamente, e pressão de operação de $91 \mathrm{kPa}$. A Tabela 2, a seguir, apresenta os resultados comparativos entre os Casos Base I e II para o circuito de moagem VMSA. Na sequência a Figura 2 ilustra as curvas de partição reais da etapa de classificação, bem como as partições por fração granulométrica para o underflow para ambos os Casos Base.

Tabela 2. Resultados comparativos entre os Casos Base I e II.

\begin{tabular}{|c|c|c|c|c|c|c|c|c|c|c|c|c|c|}
\hline \multirow{2}{*}{ Cenários } & \multirow{2}{*}{$\begin{array}{l}\text { Vazão } \\
\text { Alim. } \\
\text { (t/h) }\end{array}$} & \multirow{2}{*}{$\begin{array}{l}\mathrm{F}_{80} \\
(\mathrm{~mm})\end{array}$} & \multirow{2}{*}{$\begin{array}{c}\mathrm{P}_{80} \\
(\mathrm{~mm})\end{array}$} & \multirow{2}{*}{$\begin{array}{c}\text { Carga } \\
\text { Circulante } \\
(\%)\end{array}$} & \multirow{2}{*}{$\begin{array}{c}W I_{\text {operacional }} \\
(\mathrm{kWh} / \mathrm{t})\end{array}$} & \multirow{2}{*}{$\begin{array}{c}\mathrm{kWh} / \mathrm{t} \text { de } \\
\text { geração } \\
<0,106 \mathrm{~mm}\end{array}$} & \multicolumn{3}{|c|}{$\begin{array}{c}\text { \% Sólidos } \\
\text { Classificação }\end{array}$} & \multicolumn{3}{|c|}{ Partição para o U/F (\%) } & \multirow{2}{*}{$\begin{array}{l}\text { Eficiência } \\
\text { de Class. } \\
0,106 \mathrm{~mm} \\
(\%)\end{array}$} \\
\hline & & & & & & & Alim. & $U / F$ & $\mathrm{O} / \mathrm{F}$ & $\begin{array}{c}\text { Polpa } \\
\text { (vol) }\end{array}$ & Sólidos & Água & \\
\hline Caso Base I & 110 & 9,38 & 0,108 & 276 & 22,4 & 25,2 & 68,6 & 76,0 & 54,1 & 58,8 & 73,4 & 50,7 & 43,9 \\
\hline Caso Base II & 133 & 11,2 & 0,090 & 211 & 17,8 & 20,8 & 55,0 & 83,1 & 32,1 & 28,9 & 67,9 & 16,9 & 72,9 \\
\hline
\end{tabular}

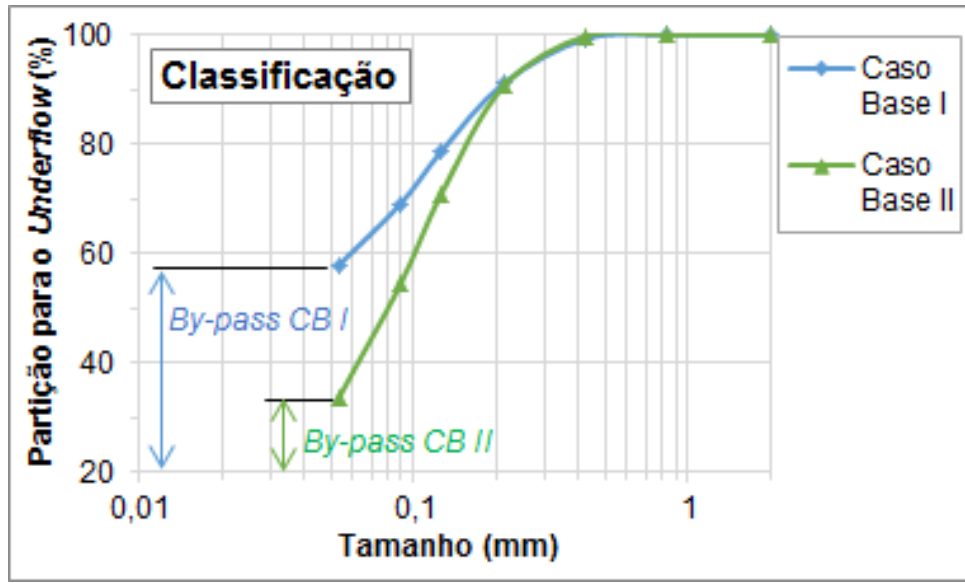

\begin{tabular}{|c|cc}
\hline $\begin{array}{c}\text { Tamanho } \\
\text { (mm) }\end{array}$ & $\begin{array}{c}\text { Partição para o } \\
\text { Underflow por Fração } \\
\text { Granulométrica (\%) }\end{array}$ \\
\hline 0,841 & 100 & 100 \\
0,424 & 99,3 & 99,8 \\
0,212 & 91,1 & 90,6 \\
0,126 & 78,7 & 71,0 \\
0,089 & 69,0 & 54,4 \\
0,053 & 58,0 & 33,8 \\
$-0,053$ & 48,2 & 13,4 \\
\hline$d_{50 C}(\mathrm{~mm})$ & 0,113 & 0,098 \\
\hline
\end{tabular}

Figura 2. Partições reais para o underflow do circuito de moagem VMSA.

Nota-se da Tabela 2 um aumento de $21 \%$ da vazão de alimentação nova de do CB I para o CB II (110 t/h para $133 \mathrm{t} / \mathrm{h}$ ), além da geração de um produto final mais fino $(0,108 \mathrm{~mm}$ para 0,090 $\mathrm{mm}$ ). Dois fatores contribuíram para tal desempenho, quais sejam: (a) o aumento do grau de enchimento do moinho de 35\% para $40 \%$ e (b) aumento da eficiência de classificação em 0,106 $\mathrm{mm}$ de $44 \%$ para $73 \%$. O segundo fato comprova os resultados previstos pelos cenários simulados, os quais indicaram redução do by-pass de finos (vide Figura 2, de $48 \%$ para $13 \%$ ) e água (de $51 \%$ para $17 \%$ ) e da carga circulante (de $276 \%$ para $211 \%$ ). 


\section{CONCLUSÃO}

As principais conclusões do presente trabalho são:

- O método utilizado baseado em amostragem industrial, modelagem e simulação demonstrou ser robusto e confiável para estudos de melhoria de processo de circuito de moagem. Contudo, é importante ressaltar que o sucesso do método depende a priori de uma representativa campanha de amostragem;

- $\quad$ A adequada operação da etapa de classificação de circuitos de moagem é essencial para um bom desempenho global do circuito. Para tanto, a alimentação da classificação deve ser o mais diluída possível, de modo a promover uma classificação com alta eficiência e baixo by-pass;

- $\quad$ O bom desempenho da etapa de classificação (Caso Base II) além de melhorar o desempenho do circuito de moagem, possibilitou o aumento da vazão de alimentação e geração de um produto final mais fino;

- $\quad$ Ainda promoveu maior liberação das partículas mistas de sílica e magnetita. Como resultado ocorreu um aumento da seletividade da etapa de concentração magnética, acarretando em eliminação ou diminuição do arraste de sílica para o concentrado magnético seja por liberação ou aprisionamento;

- Tal circunstância proporcionou aumento da recuperação de vanádio, assim como geração de um concentrado final de maior qualidade com redução significativa do teor de $\mathrm{SiO} 2$, índice de fundamental importância no processo subsequente de calcinação.

\section{REFERÊNCIAS}

LYNCH, A. J.; RAO, T. C. (1975). Modelling and Scale-Up of Hydrocyclone Classifiers. Proceedings XI Int Min Proc Congress, Cagliari.

NAGESWARARAO, K. (1978). Further developments in the modeling an scale up of industrial hydrociclones. PhD Thesis, University of Queensland (JKMRC)

NAGESWARARAO, K. (1995). A generalized model for hydrocyclone classifiers. AusIMM Proceedings, Parkville, v. 2, n. 300, 21 p.

WHITEN, W. J. (1976). Ball mill simulation using small calculators. Proceedings AusIMM, p. 47-53. 